UNIVERSITE DE LAUSANNE - FACULTE DE BIOLOGIE ET DE MEDECINE DEPARTEMENT DES SERVICES DE CHIRURGIE ET D'ANESTHESIOLOGIE Service de chirurgie viscérale

\title{
Laparoscope use and surgical site infections in digestive surgery
}

\section{THESE}

préparée sous la direction du Professeur titulaire Vincent Bettschart et présentée à la Faculté de biologie et de médecine de I'Université de Lausanne pour l'obtention du grade de

\author{
DOCTEUR EN MEDECINE
}

$$
\text { Par }
$$

Sébastien ROMY

Médecin diplômé de la Confédération Suisse

Originaire de Sorvilier (BE) 


\section{INFLUENCE DE LA LAPAROSCOPIE SUR LES INFECTIONS DU SITE CHIRURGICAL EN CHIRURGIE DIGESTIVE}

(Laparoscope use and surgical site infections in digestive surgery)

But: comparer les taux d'infections du site chirurgical (ISC) en fonction de la voie d'abord, ouverte ou laparoscopique, pour 3 procédures: l'appendicectomie, la cholécystectomie et la colectomie. Evaluer l'effet de la laparoscopie sur l'ISC pour ces trois interventions.

Contexte: la laparoscopie est associée à de nombreux avantages par rapport à la chirurgie ouverte. Parmi ceux-ci, des taux inférieurs d'ISC ont été rapportés lors de laparoscopie. Ceci a été décrit en particulier lors de cholécystectomie. Mais des biais tels que le manque de suivi après la sortie de l'hôpital, et certains facteurs confondants, auraient pu contribuer à l'observation de différences entre ces deux techniques.

Méthode : étude descriptive basée sur des données collectées entre mars 1998 et décembre 2004 de manière prospective dans le cadre d'un programme de surveillance des ISC dans 8 hôpitaux suisses. Ce programme comportait un suivi standardisé après le départ de l'hôpital. Les taux d'ISC ont été comparés après interventions faites par laparoscopie et chirurgie ouverte. Différents paramètres pouvant influencer la survenue d'une infection ont été identifiés en utilisant des modèles de régression logistiques.

Résultats : les taux d'ISC après interventions par laparoscopie et par voie ouverte ont été respectivement de $59 / 1051(5.6 \%)$ versus $117 / 1417 \quad(8.3 \%)$ après appendicectomie $(p=0.01), 46 / 2606(1.7 \%)$ versus $35 / 144 \quad(7.9 \%)$ après cholécystectomie $(p<0.0001)$, et $35 / 311$ (11.3\%) versus $400 / 1781(22.5 \%)$ après colectomie $(p<0,0001)$. Après ajustement, les interventions par laparoscopie étaient associées à un taux inférieur d'ISC : odds ratio $=0.61$ (IC 95\%:0.43-0.87) pour l'appendicectomie, $0.27(0.16-0.43)$ pour la cholécystectomie et $0.43(0.29-0.63)$ pour la colectomie.

Discussion et conclusion : bien que les patients aient quitté plus tôt l'hôpital après une intervention laparoscopique, leur suivi à un mois a été identique, ce qui a permis d'éviter une sous-estimation des ISC après chirurgie laparoscopique. De plus, l'analyse multivariée a inclus de nombreux facteurs potentiellement confondants, et l'utilisation de la laparoscopie était indépendamment et significativement liée à un effet protecteur à l'égard de l'ISC. La laparoscopie lors d'appendicectomie, cholécystectomie et colectomie semble diminuer le taux d'ISC en comparaison à la même chirurgie pratiquée par voie ouverte. Lorsqu'elle est faisable, cette voie d'abord minimalement invasive devrait être préférée à la chirurgie ouverte. 


\title{
Laparoscope Use and Surgical Site Infections in Digestive Surgery
}

\author{
Sébastien Romy, MD, *† Marie-Christine Eisenring, RN, CIC, $\neq$ Vincent Bettschart, $M D, * \dagger$ \\ Christiane Petignat, MD, $\S$ Patrick Francioli, MD, $\S$ and Nicolas Troillet, MD, MSc $\ddagger \S$
}

\begin{abstract}
Objective: To compare surgical site infection (SSI) rates in open or laparoscopic appendectomy, cholecystectomy, and colon surgery. To investigate the effect of laparoscopy on SSI in these interventions.

Background: Lower rates of SSI have been reported among various advantages associated with laparoscopy when compared with open surgery, particularly in cholecystectomy. However, biases such as the lack of postdischarge follow-up and confounding factors might have contributed to the observed differences between the 2 techniques.

Methods: This observational study was based on prospectively collected data from an SSI surveillance program in 8 Swiss hospitals between March 1998 and December 2004, including a standardized postdischarge follow-up. SSI rates were compared between laparoscopic and open interventions. Factors associated with SSI were identified by using logistic regression models to adjust for potential confounding factors.
\end{abstract}

Results: SSI rates in laparoscopic and open interventions were respectively $59 / 1051(5.6 \%)$ versus $117 / 1417(8.3 \%)$ in appendectomy $(P=0.01), 46 / 2606(1.7 \%)$ versus $35 / 444(7.9 \%)$ in cholecystectomy $(P<0.0001)$, and $35 / 311(11.3 \%)$ versus $400 / 1781$ $(22.5 \%)$ in colon surgery $(P<0.0001)$. After adjustment, laparoscopic interventions were associated with a decreased risk for SSI: $\mathrm{OR}=0.61(95 \%$ CI $0.43-0.87)$ in appendectomy, $0.27(0.16-0.43)$ in cholecystectomy, and $0.43(0.29-0.63)$ in colon surgery. The observed effect of laparoscopic techniques was due to a reduction in the rates of incisional infections, rather than in those of organ/space infections.

Conclusion: When feasible, a laparoscopic approach should be preferred over open surgery to lower the risks of SSI.

(Ann Surg 2008;247: 627-632)

From the *Department of Surgery, Mid-Valais Hospital Center, Sion, Switzerland; †Department of Surgery, University Hospital of Lausanne, Switzerland; $t$ Center for Infectious Diseases and Epidemiology, Central Institute of the Valais Hospitals, Sion, Switzerland; and $\S$ Service of Hospital Preventive Medicine, University Hospital of Lausanne, Switzerland.

Reprints: Nicolas Troillet, MD, MSc, Central Institute of the Valais Hospitals, 86, Avenue Grand-Champsec, Sion, CH 1950, Switzerland. E-mail: nicolas.troillet@ichv.ch.

Copyright (C) 2008 by Lippincott Williams \& Wilkins

ISSN: 0003-4932/08/24704-0627

DOI: $10.1097 /$ SLA.0b013e3181638609
$\mathrm{V}$ arious advantages have been reported for laparoscopic interventions when compared with open surgery. These include a shorter hospital stay after surgery, a faster recovery time, and a lower rate of surgical site infections (SSI). ${ }^{1-3}$ However, biases and confounding factors associated with observational studies may have contributed to the observed differences in these outcomes. For instance, as pointed out by Richards et al, ${ }^{3}$ the lack of postdischarge follow-up might generate a more important underestimation of SSI rates in patients who underwent laparoscopic procedures because they left the hospital earlier as those who underwent open surgery.

This study established the effect of a laparoscopic approach on SSI rates in appendectomy, cholecystectomy, and colon surgery, while using the variables available through a multicentric surveillance program that included postdischarge follow-up.

\section{METHODS}

From March 1998 to December 2004, patients undergoing appendectomy, cholecystectomy, or colon surgery in 8 hospitals in Western Switzerland (7 secondary care public hospitals and 1 tertiary care university hospital) were included in a surveillance program developed according to the principles of the U.S. National Nosocomial Infections Surveillance (NNIS) system. ${ }^{4}$

Demographic and clinical data were prospectively collected by trained infection control nurses. They included the hospital in which the patient was operated, age, gender, score of the American Society of Anesthesiologists (ASA), dates of admission and discharge, date and type of operation (procedure, emergency, laparoscopic approach), administration of prophylactic antibiotics, incision contamination class, duration of the intervention (longer or shorter as a $T$ time, as defined in the NNIS index), ${ }^{4,5}$ and whether a reintervention for another reason than SSI was performed during the follow-up period. Operations that began with a laparoscope and ended up as open surgery were considered as open surgery. Patients were followed-up during their hospital stay and postdischarge for a month. Postdischarge follow-up consisted of standardized phone interviews with the patients. Treating physicians were contacted for complementary information in case of answers that could suggest an SSI. Diagnoses of SSI were confirmed by infectious disease physicians according to the Centers for Disease Control and Prevention (CDC) defi- 
nitions. $^{6,7}$ SSIs were classified as incisional (superficial or deep) or organ/space infections.

Data were entered in Epi-info (World Health Organization [WHO], Geneva and CDC, Atlanta). Statistics were done with the SAS software (Release 8.2, SAS Institute, Cary, NC). SSI rates, mean lengths of stay, and proportions of interventions with an available 1-month follow-up were compared between surgical techniques (laparoscopic or open procedures). Risk factors for SSI were determined by comparing patients who suffered from SSI with those who did not. Statistically significant risk factors for SSI were then compared between patients who underwent laparoscopic procedures and those who were operated using open surgery. Fisher exact, $\chi^{2}$, Mantel-Haenszel, $t$, or Wilcoxon tests were used as appropriate for univariate analyses. Adjustment for confounding factors was done by including all available potential risk factors for SSI as candidate covariates in forward stepwise logistic regressions with $P \leq 0.2$ being the criteria for entry into the model and $P \leq 0.05$ being the criteria for remaining in it. All SSI, incisional SSI, and organ/space SSI were analyzed separately. Hospitals were dummy-coded and hospital $F$ was considered the reference. All tests were 2 -tailed. $P \leq 0.05$ was considered significant.

\section{RESULTS}

The included interventions were 2468 appendectomies, of which $1051(42.6 \%)$ were performed with a laparoscope, 3096 cholecystectomies, of which 2652 (85.6\%) were performed with a laparoscope, and 2092 operations of the colon, of which $311(14.9 \%)$ were performed with a laparoscope. The median lengths of stay in laparoscopic and open interventions were respectively 4 days (interquartile range, IQR $=3$ ) versus 5 days $(\mathrm{IQR}=3)$ in appendectomy $(P<0.0001), 5$ days $(\mathrm{IQR}=3)$ versus 11 days $(\mathrm{IQR}=8)$ in cholecystectomy $(P<0.0001)$, and 10 days $(\mathrm{IQR}=5)$ versus 16 days $(\mathrm{IQR}=$ $11)$ in colon surgery $(P<0.0001)$. Follow-up at 1 month was available in $976 / 1051(92.9 \%)$ of the appendectomies done

TABLE 1. Appendectomy: Characteristics of Patients and Surgical Interventions, Risk Factors for SSI (Univariate Analysis)

\begin{tabular}{|c|c|c|c|c|}
\hline Characteristic & $\begin{array}{c}\text { Total } \\
(\mathrm{n}=2468)\end{array}$ & $\begin{array}{c}\text { SSI } \\
(\mathrm{n}=176)\end{array}$ & $\begin{array}{c}\text { No SSI } \\
(n=2292)\end{array}$ & $P$ \\
\hline Male gender, $\mathrm{N}(\%)^{*}$ & $1331(53.9)$ & $110(62.5)$ & $1221(53.3)$ & 0.02 \\
\hline Age in years, mean $(\mathrm{SD})^{*}$ & $32.7(18.4)$ & $37.5(19.7)$ & $32.4(18.2)$ & 0.0004 \\
\hline Duration of the operation $>T, \mathrm{~N}(\%)^{* \dagger}$ & $575(23.3)$ & $79(44.9)$ & $496(21.6)$ & $<0.0001$ \\
\hline$>1$ procedure during the operation, $\mathrm{N}(\%)$ & $42(1.7)$ & $2(1.1)$ & $40(1.8)$ & 0.77 \\
\hline Re-intervention $\leq 1$ mo for a noninfectious complication, $N(\%)$ & $27(1.1)$ & $8(4.6)$ & $19(0.8)$ & 0.0004 \\
\hline Delay from admission to operation in days, mean (SD) & $0.50(7.4)$ & $0.36(0.69)$ & $0.51(7.67)$ & 0.75 \\
\hline Emergency procedure, N (\%) & $2316(93.8)$ & $164(93.2)$ & $2152(93.4)$ & 0.63 \\
\hline Antibiotics before incision, N (\%) & $1468(59.5)$ & $106(60.2)$ & $1362(59.4)$ & 0.87 \\
\hline Laparoscopic technique, $\mathrm{N}(\%)$ & $1051(42.6)$ & $59(33.5)$ & $992(43.3)$ & 0.01 \\
\hline SSI by ASA score, $\mathrm{N} /$ total $(\%)$ & & & & 0.05 \\
\hline 1 & & $85 / 1238(6.9)$ & & \\
\hline 2 & & $68 / 1087(6.3)$ & & \\
\hline 3 & & $23 / 132(17.4)$ & & \\
\hline 4 & & $0 / 11(0)$ & & \\
\hline 5 & & $0 / 0(0)$ & & \\
\hline SSI by contamination class $*$, N/total $(\%)$ & & & & $<0.0001$ \\
\hline 1 & & $0 / 0(0)$ & & \\
\hline II & & $23 / 689(3.3)$ & & \\
\hline III & & $44 / 1100(4.0)$ & & \\
\hline IV & & $109 / 679(16.1)$ & & \\
\hline SSI by hospital, N/total (\%) & & & & 0.12 \\
\hline A & & $21 / 312(6.7)$ & & \\
\hline $\mathrm{B}$ & & $22 / 236(9.3)$ & & \\
\hline $\mathrm{C}$ & & $13 / 190(6.8)$ & & \\
\hline $\mathrm{D}$ & & $14 / 226(6.2)$ & & \\
\hline $\mathrm{E}$ & & $27 / 293(9.2)$ & & \\
\hline $\mathrm{F}$ & & $49 / 887(5.5)$ & & \\
\hline $\mathrm{G}$ & & $24 / 228(10.5)$ & & \\
\hline $\mathrm{H}$ & & $6 / 96(6.3)$ & & \\
\hline
\end{tabular}


by laparoscopy versus $1319 / 1416(93.2 \%)$ of those done by open surgery $(P=0.81)$. These proportions were $2547 / 2652$ $(96.0 \%)$ versus $428 / 444(96.4 \%)$ for cholecystectomy $(P=$ $0.79)$, and $305 / 311(98.1 \%)$ versus $1704 / 1781(95.7 \%)$ for colon surgery $(P=0.06)$.

SSI rates in laparoscopic and open interventions were respectively $59 / 1051(5.6 \%)$ versus $117 / 1417(8.3 \%)$ for appendectomy $(P=0.01), 46 / 2652(1.7 \%)$ versus $35 / 444$ $(7.9 \%)$ for cholecystecomy $(P<0.0001)$, and $35 / 311$ $(11.3 \%)$ versus $400 / 1781(22.5 \%)$ for colon surgery $(P<$ $0.0001)$. Figures for incisional SSI rates were $22 / 1051(2.1 \%)$ versus $82 / 1417(5.8)$ in appendectomy $(P<0.0001), 34 / 2652$ $(1.3 \%)$ versus $25 / 444(5.6 \%)$ in cholecystectomy $(P<$ $0.0001)$, and $15 / 311(4.8 \%)$ versus $281 / 1781(15.8 \%)$ in colon surgery $(P<0.0001)$. Organ/space SSI were also less frequent in laparoscopic than in open cholecystectomy: 12/ $2652(0.5 \%)$ versus $10 / 444(2.3 \%), P=0.0004$. But the rates of organ/space SSI did not differ significantly between laparoscopic and open appendectomy or colon surgery: $37 / 1051$
$(3.5 \%)$ versus $35 / 1417(2.5 \%), P=0.15$, and $20 / 311(6.4 \%)$ versus $119 / 1781(6.7 \%), P=1.0$, respectively.

Characteristics of the patients and interventions, and the results of the univariate analysis of risk factors for SSI are presented in Tables 1-3. Despite differences in risk factors for SSI between patients who underwent laparoscopic interventions and those operated using open surgery, laparoscopic interventions were associated with a lower risk of SSI in the 3 studied operations, independently of other factors such as the ASA score, the contamination class, the duration of the operation, antibiotic prophylaxis, or others (Tables 4-6). When only incisional SSI was considered, laparoscopy remained an independent protective factor in multivariate analyses addressing appendectomy, cholecystectomy, and colon surgery: $\mathrm{OR}=0.32(\mathrm{CI} 95 \% 0.19-0.53), 0.26(0.15-0.46)$, and $0.31(0.18-0.53)$, respectively. In contrast, laparoscopy was not retained in multivariate models developed to detect factors independently associated with organ/space SSI in none of the 3 studied interventions.

TABLE 2. Cholecystectomy: Characteristics of Patients and Surgical Interventions, Risk Factors for SSI (Univariate Analysis)

\begin{tabular}{|c|c|c|c|c|}
\hline & $\begin{array}{c}\text { Total } \\
(n=3096)\end{array}$ & $\begin{array}{c}\text { SSI } \\
(\mathbf{n}=\mathbf{8 1})\end{array}$ & $\begin{array}{c}\text { No SSI } \\
(n=3015)\end{array}$ & $P$ \\
\hline Male gender, $N(\%)$ & $1092(35.3)$ & $35(43.0)$ & $1057(35.0)$ & 0.16 \\
\hline Age in years, mean $(\mathrm{SD})^{*}$ & $55.3(17.0)$ & $59.6(19.9)$ & $55.2(17.0)$ & 0.02 \\
\hline Duration of the operation $>T, \mathrm{~N}(\%)^{* \dagger}$ & $327(10.6)$ & $16(19.8)$ & $311(10.3)$ & 0.02 \\
\hline$>1$ procedure during the operation, $N(\%)$ & $186(6.0)$ & $9(11.1)$ & $177(5.9)$ & 0.06 \\
\hline Reintervention $\leq 1$ mo for a noninfectious complication, $N(\%)$ & $43(1.4)$ & $5(6.2)$ & $38(1.3)$ & 0.005 \\
\hline Delay from admission to operation in days, mean (SD) & $1.7(3.3)$ & $2.2(5.1)$ & $1.7(3.3)$ & 0.15 \\
\hline Emergency procedure, N (\%) & $498(16.1)$ & $18(22.2)$ & $480(15.9)$ & 0.13 \\
\hline Antibiotics before incision, $\mathrm{N}(\%)$ & $1528(49.4)$ & $35(43.2)$ & $1493(49.5)$ & 0.31 \\
\hline Laparoscopic technique, $\mathrm{N}(\%)$ & $2652(85.7)$ & $46(56.8)$ & $2606(86.4)$ & $<0.0001$ \\
\hline SSI by ASA score, $\mathrm{N} /$ total $(\%)^{*}$ & & & & 0.0001 \\
\hline 1 & & $12 / 731(1.6)$ & & \\
\hline 2 & & $35 / 1862(1.9)$ & & \\
\hline 3 & & $30 / 459(6.5)$ & & \\
\hline 4 & & $4 / 44(9.1)$ & & \\
\hline 5 & & $0 / 0$ & & $<0.0001$ \\
\hline \multicolumn{5}{|l|}{ SSI by contamination class, N/total $(\%)^{*}$} \\
\hline I & & $0 / 0$ & & \\
\hline Il & & $51 / 2312(2.2)$ & & \\
\hline III & & $16 / 641(2.5)$ & & \\
\hline IV & & $14 / 143(9.8)$ & & \\
\hline SSl by hospital, N/total (\%) & & & & 0.2 \\
\hline A & & $8 / 409(2.0)$ & & \\
\hline $\mathrm{B}$ & & $7 / 341(2.1)$ & & \\
\hline $\mathrm{C}$ & & $10 / 343(2.9)$ & & \\
\hline $\mathrm{D}$ & & $13 / 254(5.1)$ & & \\
\hline $\mathrm{E}$ & & $8 / 348(2.3)$ & & \\
\hline $\mathrm{F}$ & & $27 / 950(2.8)$ & & \\
\hline $\mathrm{G}$ & & $7 / 318(2.2)$ & & \\
\hline $\mathrm{H}$ & & $1 / 133(0.8)$ & & \\
\hline
\end{tabular}


TABLE 3. Colon Surgery: Characteristics of Patients and Surgical Interventions, Risk Factors for SSI (Univariate Analysis)

\begin{tabular}{|c|c|c|c|c|}
\hline & $\begin{array}{c}\text { Total } \\
(n=2092)\end{array}$ & $\begin{array}{c}\text { SSI } \\
(n=435)\end{array}$ & $\begin{array}{c}\text { No SSI } \\
(\mathrm{n}=1657)\end{array}$ & $P$ \\
\hline Male gender, $N(\%)$ & $1032(49.3)$ & $236(54.3)$ & $796(48.0)$ & 0.02 \\
\hline Age in years, mean (SD)* & $65.3(14.9)$ & $65.8(14.0)$ & $65.2(15.1)$ & 0.46 \\
\hline Duration of the operation $>T, N(\%)^{* \dagger}$ & $723(34.6)$ & $174(40.0)$ & $549(33.1)$ & 0.008 \\
\hline$>1$ procedure during the operation, $N(\%)$ & $549(26.2)$ & $127(29.2)$ & $422(25.5)$ & 0.13 \\
\hline Re-intervention $\leq 1$ mo for a non-infectious complication, $N(\%)$ & $95(4.5)$ & $33(7.6)$ & $62(3.7)$ & 0.001 \\
\hline Delay from admission to operation in days, mean (SD) & $3.3(9.9)$ & $3.1(6.7)$ & $3.3(10.7)$ & 0.06 \\
\hline Emergency procedure, $\mathrm{N}(\%)^{*}$ & $438(20.9)$ & $129(29.7)$ & $309(18.7)$ & $<0.0001$ \\
\hline Antibiotics before incision, $\mathrm{N}(\%)$ & $1589(76.0)$ & $320(73.6)$ & $1270(76.6)$ & 0.19 \\
\hline Laparoscopic technique, $\mathrm{N}(\%)$ & $311(14.9)$ & $35(8.1)$ & $276(16.7)$ & $<0.0001$ \\
\hline SSI by ASA score, N/total $(\%)^{*}$ & & & & 0.0002 \\
\hline 1 & & $35 / 255(13.7)$ & & \\
\hline 2 & & $211 / 1058(19.9)$ & & \\
\hline 3 & & $157 / 657(23.9)$ & & \\
\hline 4 & & $31 / 120(25.8)$ & & \\
\hline 5 & & $1 / 2(50.0)$ & & \\
\hline SSI by contamination class, $N /$ total $(\%)^{*}$ & & & & $<0.0001$ \\
\hline $\mathrm{I}$ & & $0 / 0(0)$ & & \\
\hline II & & $267 / 1534(17.5)$ & & \\
\hline III & & $47 / 183(25.7)$ & & \\
\hline IV & & $120 / 375(32.0)$ & & \\
\hline SSI by hospital, N/total (\%) & & & & $<0.0001$ \\
\hline A & & $30 / 179(16.8)$ & & \\
\hline $\mathrm{B}$ & & $34 / 128(26.6)$ & & \\
\hline $\mathrm{C}$ & & $37 / 226(16.4)$ & & \\
\hline $\mathrm{D}$ & & $19 / 114(16.7)$ & & \\
\hline $\mathrm{E}$ & & $24 / 158(15.2)$ & & \\
\hline $\mathrm{F}$ & & $219 / 947(23.1)$ & & \\
\hline $\mathrm{G}$ & & $67 / 243(27.6)$ & & \\
\hline $\mathrm{H}$ & & $5 / 97(5.2)$ & & \\
\hline
\end{tabular}

TABLE 4. Multivariate Analysis of Risk Factors for SSI After Appendectomy

\begin{tabular}{lcc}
\hline Variable & OR (CI 95\%) & $P$ \\
\hline $\begin{array}{l}\text { Duration of the operation }>\mathrm{T}^{*} \\
\text { Reintervention } \leq 1 \text { mo for a }\end{array}$ & $2.51(1.76-3.60)$ & $<0.0001$ \\
$\quad$ noninfectious complication & $3.89(1.56-9.69)$ & 0.004 \\
Contamination class & $2.38(1.85-3.06)$ & $<0.0001$ \\
Hospital B $^{\dagger}$ & $1.92(1.16-3.18)$ & 0.01 \\
Hospital $\mathrm{E}^{\dagger}$ & $1.76(1.09-2.84)$ & 0.02 \\
Hospital & $1.66(1.02-2.70)$ & 0.04 \\
Laparoscopic technique & $0.61(0.43-0.87)$ & 0.006 \\
\hline
\end{tabular}

$* T=2 \mathrm{~h}$.

${ }^{\dagger}$ Reference $=$ hospital $\mathrm{F}$

Additional analyses on antibiotic prophylaxis showed that it was evenly administered in laparoscopic and open appendectomy $(59 \%$ vs. $60 \%, P=0.68)$, less frequently administered in laparoscopic than open cholecystectomy
TABLE 5. Multivariate Analysis of Risk Factors for SSI After Cholecystectomy

\begin{tabular}{lcc}
\hline Variable & OR (CI 95\%) & $P$ \\
\hline $\begin{array}{l}\text { Reintervention } \leq 1 \text { mo for a } \\
\text { noninfectious complication }\end{array}$ & $4.20(1.51-11.7)$ & 0.006 \\
ASA score & $1.63(1.18-2.26)$ & 0.003 \\
Hospital D* & $2.01(1.08-3.75)$ & 0.027 \\
Laparoscopic technique & $0.27(0.16-0.43)$ & $<0.0001$ \\
\hline \multicolumn{2}{c}{ *Reference = hospital F. } & \\
\hline
\end{tabular}

(48\% vs. $58 \%, P<0.0001$ ), and more often administered in laparoscopic than open colon surgery (86\% vs. $74 \%, P<$ 0.0001 ). Antibiotic prophylaxis varied also between hospitals from $46 \%$ to $81 \%$ in appendectomy $(P<0.0001)$ and from $63 \%$ to $89 \%$ in colon surgery $(P<0.0001)$. The hospitals positively associated with SSI in multivariate analyses were nevertheless not the ones with the lowest proportions of patients receiving antibiotic prophylaxis $(\mathrm{B}=56 \%, \mathrm{E}=$ 


\begin{tabular}{lcc}
\hline \multicolumn{3}{l}{ TABLE 6. Multivariate Analysis of Risk Factors for SSI After } \\
Colon Surgery \\
\hline Variable & OR (CI 95\%) & $P$ \\
\hline Duration of the operation $>\mathrm{T}^{*}$ & $1.39(1.11-1.76)$ & 0.005 \\
Reintervention $\leq 1$ mo for a & $2.27(1.42-3.60)$ & 0.0005 \\
$\quad$ non-infectious complication & & \\
Contamination class & $1.50(1.31-1.70)$ & $<0.0001$ \\
ASA score & $1.17(1.01-1.36)$ & 0.04 \\
Male gender & $1.26(1.02-1.57)$ & 0.04 \\
Hospital $\mathrm{E}^{\dagger}$ & $0.61(0.38-0.96)$ & 0.03 \\
Hospital $\mathrm{G}^{\dagger}$ & $1.50(1.09-2.06)$ & 0.01 \\
Hospital $\mathrm{H}^{\dagger}$ & $0.16(0.06-0.40)$ & 0.0001 \\
Laparoscopic technique & $0.43(0.29-0.63)$ & $<0.0001$ \\
\hline \multirow{2}{*}{$T=3 \mathrm{~h}}$. & & \\
$\quad{ }^{\dagger}$ Reference $=$ hospital F. & & \\
\hline
\end{tabular}

$81 \%, \mathrm{G}=69 \%$ in appendectomy, and $\mathrm{G}=81 \%$ in colon surgery).

\section{DISCUSSION}

This observational study found statistically significant lower rates of SSI after laparoscopic surgical interventions when compared with open interventions in appendectomy, cholecystectomy, and colon surgery.

Although patients operated with a laparoscopic technique left the hospital earlier than the others, their follow-up at 1 month did not differ for appendectomies and cholecystectomies. It even tended to be better after laparoscopic than after open colon surgery. It was carefully and systematically conducted by independent infection control nurses and available for more than $90 \%$ of the patients who underwent appendectomy, and more than $95 \%$ of those who underwent cholecystectomy or colon surgery. Thus, in contrast to the study by Richards et $a l^{3}$ no underestimation of SSI due to a lack of follow-up in patients operated with a laparoscopic technique could explain the observed differences in SSI rates in the present study.

Moreover, the nested case-control design used to confirm the protective effect of laparoscope for SSI revealed that the laparoscopic approach remained significantly associated with a lower risk of SSI after adjusting for potential confounding factors in multivariate analyses that included not only the components of the NNIS index, but also variables such as the patients' age and gender, the delay from their admission to operation, emergency operations, antibiotic prophylaxis, reoperations for a noninfectious complication, and the hospital in which the intervention took place.

Antibiotic prophylaxis should be administered before incision in every appendectomy and operation on the colon but is recommended only for high-risk situations in cholecystectomy. $^{8}$ The proportions of patients who had received antibiotics before incision in this study were found insufficient in appendectomy (59.5\%) and colon surgery (76\%). These low unsatisfying figures could be due to difficulties in data collection linked to the absence of a computerized prescribing system in most of the participating hospitals, to delayed or early administration of antibiotics that were not considered as a prophylaxis and thus not entered in case report forms, or to the absence of their administration. Antibiotic prophylaxis significantly varied between hospitals, but hospitals associated with higher risks of SSI were not those with the lowest proportion of patients receiving it. Antibiotic prophylaxis did not differ between laparoscopic and open appendectomy and was less administered in laparoscopic than open cholecystectomy, thus not contributing to any overestimation of the protective effect of laparoscopy in these interventions. It was more often administered in laparoscopic than open colon surgery but was surprisingly not significantly associated with SSI, neither in univariate nor multivariate analyses, thus probably not contributing to any confounding of the effect of laparoscopy on SSI.

Appendectomy is by definition an emergency procedure but, because of patients not operated on the day of their admission, was recorded as such in $93.8 \%$ of cases only. In any case, emergency interventions were associated with SSI in colon surgery only, and in univariate but not in multivariate analysis. This could be due to the fact that emergency was taken into account in multivariate models through high contamination classes that included perforated or abscessed acute sigmoiditis.

It is worth noting that, in appendectomy and colon surgery, most of the differences in SSI rates observed in our study between laparoscopic or open interventions were due to lower rates of incisional, but not intraperitoneal (organ/space) infections, whereas both incisional and organ/space infections were less frequent in laparoscopic cholecystectomy. However, in multivariate analyses adjusting for confounding factors, laparoscope use remained an independent protective factor only for incisional SSI, in cholecystectomy too. In contrast to the study by Biscione et a1, ${ }^{9}$ who found that laparoscopy was associated with a lower risk of incisional and organ/space infections, our findings suggest that, among the various existing theories on the protective effect of laparoscopy, the smaller incision leading to a reduced exposure of the abdominal wall plays a more important role than the preservation of the immune function and the reduction of the inflammatory response to tissue injury that have been found in experimental studies. ${ }^{10,11}$ Boni et $\mathrm{a}^{12}$ found even in their review that, although associated with lower rates of SSI, laparoscopic surgery seemed characterized by a higher incidence of postoperative intra-abdominal abscesses.

Interestingly, apart from undergoing a laparoscopic operation or a reintervention for a noninfectious complication, factors independently associated with SSI in multivariate analyses differed between the interventions. For example, all the 3 components of the NNIS index (contamination class, duration of the operation, and ASA score) were associated with SSI in colon surgery, whereas the ASA score did not predict SSI in appendectomy, neither did contamination class or the duration of the operation in cholecystectomy. In addition, the gender seemed to matter only in colon surgery and no hospital was systematically associated with higher or lower rates of SSI. This illustrates the difficulty to apply the 1991 NNIS basic risk index to all kinds of surgical procedures, trying to adjust for factors linked to the patient or the 
procedure itself, but not to quality of care, while comparing hospitals or surgeons between them. As stated by Gaynes et al, ${ }^{2}$ there is still room for improvement in risk indexes. For instance, procedure specific risk indexes have been proposed in coronary artery bypass graft surgery and knee arthroplasty, ${ }^{13-15}$ and, because it was associated with lower rates of SSI, the use of a laparoscope has recently been identified in the NNIS system as a factor that should modify the basic 1991 risk index in cholecystectomy, colon surgery, appendectomy, and gastric surgery. ${ }^{2}$

This difficulty to perform the right adjustment for case-mix when comparing SSI rates also constitutes a limitation of the present study. Indeed, despite our use of multivariate logistic regressions, considered a better method than matching in case-control studies, ${ }^{16}$ the available candidate covariates put into the models may well not have captured all potential confounding factors. The male gender detected as a risk factor for SSI in colon surgery might for instance be confounded by the presence of colon cancer, more frequent in men. Furthermore, since this study was observational and the decision of surgeons to use a laparoscopic or an open approach was not random, unknown confounding factors may have been unbalanced between patients who underwent laparoscopic interventions and those who had open surgery. For example, obesity, cancer, or the lack of training could have influenced the surgeons' choice toward open surgery and could be factors independently associated with SSI. However, such selection biases were probably less prominent in appendectomy and cholecystectomy than in colon surgery. Finally, the lack of information on conversions from laparoscopic to open surgery during the intervention hindered an intentionto-treat analysis and might have contributed to an overestimation of the protective effect of laparoscopy. But conversion rates have been shown by others to be quite low in laparoscopic digestive surgery. They were $3 \%$ to $4 \%$ in cholecystectomy, ${ }^{17} 7 \%$ to $12 \%$ in appendectomy, ${ }^{18,19}$ and $10 \%$ in colon surgery. ${ }^{20}$ It is thus unlikely that an intentionto-treat analysis would have significantly change the results of the present study.

In conclusion, among other advantages, the laparoscopic approach in appendectomy, cholecystectomy, and colon surgery seems to lower the risk of SSI when compared with open surgery. When feasible, this minimal invasive technique should thus be preferred to open surgery.

\section{ACKNOWLEDGMENTS}

The authors thank the infection control nurses, the infectious disease physicians, and the surgeons who participated in the surveillance program for surgical site infections implemented in their hospitals. This study would not have been possible without their work and commitment.

\section{REFERENCES}

1. Donohue JH. Laparoscopic surgical procedures. Mayo Clin Proc. 1994; 69:758-762.

2. Gaynes RP, Culver DH, Horan TC, et al. Surgical site infection (SSI) rates in the United States, 1992-1998: the National Nosocomial Infections Surveillance System basic SSI risk index. Clin Infect Dis. 2001; 33(suppl 2):S69-S77.

3. Richards C, Edwards J, Culver D, et al. Does using a laparoscopic approach to cholecystectomy decrease the risk of surgical site infection? Ann Surg. 2003;237:358-362.

4. Emori TG, Culver DH, Horan TC, et al. National nosocomial infections surveillance system (NNIS): description of surveillance methods. Am J Infect Control. 1991;19:19-35.

5. Culver DH, Horan TC, Gaynes RP, et al. Surgical wound infection rates by wound class, operative procedure, and patient risk index. National Nosocomial Infections Surveillance System. Am J Med. 1991;91(suppl B): $152 \mathrm{~S}-157 \mathrm{~S}$.

6. Garner JS, Jarvis WR, Emori TG, et al. CDC definitions for nosocomial infections, 1988. Am J Infect Control. 1988;16:128-140.

7. Horan TC, Gaynes RP, Martone WJ, et al. CDC definitions of nosocomial surgical site infections, 1992: a modification of CDC definitions of surgical wound infection. Infect Control Hosp Epidemiol. 1992;13:606608 .

8. Anonymous. Antimicrobial prophylaxis for surgery. Treat Guidel Med Lett. 2004;2:27-32.

9. Biscione FM, Couto RC, Pedrosa TM, et al. Factors influencing the risk of surgical site infection following diagnostic exploration of the abdominal cavity. $J$ Infect. 2007:55:317-323.

10. Balague Ponz C, Trias M. Laparoscopic surgery and surgical infection. I Chemother. 2001;13(suppl 1):17S-22S.

11. Buunen M, Gholghesaei M, Veldkamp R, et al. Stress response to laparoscopic surgery: a review. Surg Endosc. 2004;18:1022-1028.

12. Boni L, Benevento $A$, Rovera $F$, et al. Infective complications in laparoscopic surgery. Surg Infect. 2006;7(suppl 2):109S-111S.

13. Russo PL, Spelman DW. A new surgical-site infection risk index using risk factors identified by multivariate analysis for patients undergoing coronary artery bypass graft surgery. Infect Control Hosp Epidemiol. $2002 ; 23: 372-376$.

14. Harrington G, Russo PL, Spelman DW, et al. Surgical-site infection rates and risk factor analysis in coronary artery bypass graft surgery. Infect Control Hosp Epideniol. 2004;25:472-476.

15. Minnema B, Vearncombe $M$, Augustin A, et al. Risk factors for surgical-site infection following primary total knee arthroplasty. Infect Control Hosp Epidemiol. 2004;25:477-480.

16. Rothman KJ, Greenland S. Matching. In: Rothman KJ, Greenland S, eds. Modern Epidemiology. 2nd ed. Philadelphia: Lippincott-Raven; 1998.

17. Ackland MJ, Jolley DJ, Ansari MZ. Postoperative complications of cholecystectomy in Victorian public hospitals. Aust N ZJ Public Health. 1996;20:583-588.

18. Yong JL, Law WL, Lo CY, et al. A comparative study of routine laparoscopic versus open appendectomy. JSLS. 2006;10:188-192.

19. Hellberg A, Rudberg C, Enochsson L, et al. Conversion from laparoscopic to open appendicectomy: a possible drawback of the laparoscopic technique? Eur I Surg. 2001;167:209-213.

20. Tekkis PP, Senagore AJ, Delaney CP. Conversion rates in laparoscopic colorectal surgery: a predictive model with 1253 patients. Surg Endosc. $2005 ; 19: 47-54$ 